\title{
PANDU LOKASI WISATA KOTA TANGERANG DENGAN SISTEM INFORMASI GEOGRAFIS BERBASIS WEB
}

\author{
Sugeng Santoso ${ }^{1}$, Ilamsyah ${ }^{2}$, Rio Abilaji ${ }^{3}$ \\ Jurusan Teknik Informatika, STMIK Raharja; \\ Jl. Jend. Sudirman no.40 Modern Cikokol-Tangerang, 021-5529692 \\ e-mail: sugeng.santoso.@raharja.info ${ }^{1}$,ilamsyah@raharja.info ${ }^{2}$, \\ rio.abilaji@raharja.info ${ }^{3}$
}

\begin{abstract}
Around the tourists who come to the city of Tangerang at this time makes the problem faced by the Tangerang Culture and Tourism Office. To help solve the problem faced, the author designed a web-based geographic information system (GIS) which would later help tourists in finding tourist locations in the city of Tangerang easily and precisely. The advantages of this web service can be used to solve the problems that exist in the Tangerang City Culture and Tourism Office and help tourists in obtaining tourist information, looking for attractions, displaying the path to the desired tourist attractions as well as providing photographs of interesting attractions. So that it can increase public interest or tourists who will visit to tour the city of Tangerang. The research methodology uses a prototyping approach and the system design uses UML (Unifed Modeling Language).
\end{abstract}

Keyword: Geographic Information System, Tangerang, Tourist Sites

\section{PENDAHULUAN}

Dengan berkembangnya teknologi dan komunikasi saat ini membawa perubahan dalam berbagai sektor, termasuk juga dalam sektor pariwisata. Dimana pariwisata merupakan perjalanan seseorang atau kelompok orang ke suatu tempat tujuan yang berbeda di luar tempat kerja atau tempat tinggal sehari-hari untuk berlibur. Dengan sistem yang berjalan saat ini belum mempermudah masyarakat atau wisatawan yang ingin berkunjung atau melihat wisata di kota Tangerang, dikarenakan informasi wisata yang di sediakan belum mempermudah wisatawan untuk mendapatkan informasi seputar wisata yang berada di kota Tangerang.

Hal ini akan menjadi tugas pokok dan fungsi dari Dinas Budaya dan Pariwisata kota Tangerang pada seksi pelayanan informasi yang bertanggung jawab dalam pemberitahuan informasi mengenai lokasi wisata di daerah Kota Tangerang, sehingga masyarakat dapat dengan mudah mengakses lokasi dan informasi wisata di Kota Tangerang. 
Dari gambaran masalah tersebut maka diperlukan adanya suatu sistem informasi berbasis web yang menyediakan informasi mengenai lokasi wisata di Kota Tangerang.Salah satu penyajian informasi pariwisata ini adalah melalui penayangan dalam bentuk data atau informasi yang dikaitkan dengan kondisi geografis di wilayah kota Tangerang, sistem ini sering di kenal dengan Sistem Informasi Geografis (SIG). Dengan adanya sistem informasi geografis berbasis web tersebut akan memberikan alternatif kemudahan kepada masyarakat untuk mencari informasi mengenai lokasi dan informasi wisata yang ada di Kota Tangerang serta memberi kemudahan kepada Dinas Budaya dan Pariwisata Kota Tangerang dalam mengolah data informasi lokasi wisata di daerah Kota Tangerang.

\section{PERMASALAHAN}

Permasalahan yang dihadapai Dinas Budaya dan Pariwisata Kota Tangerang adalah masih terbatasnya objek wisata yang sudah tertata, besarnya potensi objek wisata yang ada di kota Tangerang ternyata tidak diimbangi dengan berkembangnya teknologi sistem informasi geografis selain itu banyak potensi wisata yang sudah tertata ternyata masih belum maksimal dalam penyajiannya.

\section{LITERATURE REVIEW}

Banyak penelitian yang sebelumnya dilakukan mengenai Sistem Informasi Geografis (SIG). Dalam upaya pengembangan sistem informasi geografis ini perlu dilakukan studi pustaka sebagai salah satu dari penerapan metode penelitian yang dilakukan. Diantaranya adalah mengidentifikasikan kesenjanga (identify gaps), menghindari pembuatan ulang (reinventing the wheel), mengidentifikasikan metode yang pernah dilakukan, meneruskan penelitian sebelumnya, serta mengetahui orang lain yang spesialisasi dan area penelitiannya sama dibidang ini. Beberapa literature review tesebut adalah sebagai berikut :

1. Tinjauan studi dari penelitian Supriati., Santoso \& Juniarno, 2014, STMIK Raharja, Tangerang, dalam jurnal Jurnal Teknik Informatika Dan Sistem Informasi Vol.1/No.1

[Supriati., Santoso., dan Juniarno 2014] dalam jurnal Jurnal Teknik Informatika Dan Sistem Informasi Vol.1/No.1 berjudul Pemanfaatan Sistem Informasi 
Geografis Berbasis Web Untuk Penyebaran Lokasi Puskesmas Di Kota Tangerang. Penelitian ini menjelaskan tentang sistem geografis berbasis web yang menyediakan informasi lokasi puskesmas yang berada di kota tangerang. Dalam mencari membutuhkan letak atau posisi yang dikenal sebagai informasi geografis. Dalam perancangan dan pengembangan aplikasi tersebut menggunakan sumber data kota tangerang yang di dapakan dari Google Maps API dan data lokasi puskesmas yang didapat dari dinas kesehatan Kota Tangerang serta puskesmas kota Tangerang.

2. Tinjauan studi dari penelitian Masykur, F, 2014, Universitas Muhammadiyah Ponorogo, dalam Simetris Jurnal Teknik Mesin, Elektro dan Ilmu Komputer Vol.5/No.2

[Masykur, F 2014] dalam Simetris Jurnal Teknik Mesin, Elektro dan Ilmu Komputer Vol.5/No.2, berjudul Implementasi Sistem Informasi Geografis Menggunakan Google Maps Api Dalam Pemetaan Asal Mahasiswa. Penelitian ini menjelaskan tentang Sistem Informasi Geografis merupakan bidang ilmu yang membahas bidang geografis kebumian yang bisa diterapkan dalam berbagai bidang institusi, misalnya di bidang kemiliteran, bidang kedokteran, bidang pendidikan hingga bidang pertanian. Salah satu dari manfaat dari Sistem Informasi Geografis adalah pemetaan mahasiswa di Fakultas Teknik Universitas Muhammadiyah Ponorogo. Pemetaan mahasiswa tersebut dilakukan dengan memanfaat peta yang sudah disediakan oleh google yakni google Maps API. Google Maps adalah suatu peta dunia yang dapat kita gunakan untuk melihat suatu daerah. Dengan kata lain, google Maps merupakan suatu peta yang dapat dilihat dengan menggunakan suatu browser. Kita dapat menambahkan fitur google Maps dalam web yang telah kita buat atau pada blog kita yang berbayar maupun gratis sekalipun dengan google Maps API.

3. Tinjauan studi dari penelitian Dyah, N. R., \& Arsandy, E. R. 2015, Universitas Ahmad Dahlan Yogyakarta, dalam Informatika Mulawarman Jurnal Ilmiah Ilmu Komputer Vol.10/No.1

[Dyah, N.R., \& Arsandy, E. R 2015] dalam Informatika Mulawarman Jurnal Ilmiah Ilmu Komputer Vol.10/No.1 berjudul Sistem Informasi Geografis Tempat Praktek Dokter Spesialis Di Provinsi Di Yogyakarta Berbasis Web. 
Penelitian ini menjelaskan tentang Kebutuhan akan mendapatkan suatu informasi secara cepat dan tepat, telah menjadi kebutuhan pokok masyarakat apalagi berhubungan dengan keputusan untuk memilih tempat layanan kesehatan. Subjek penelitian ini adalah website Sistem Informasi Gerografis Tempat Praktik Dokter Spesialis di Provinsi D.I. Yogyakarta.Hasil dari penelitian ini adalah sebuah sistem informasi geografis yang dapat memberikan kemudahan bagi masyarakat tentang berita kesehatan, tips kesehatan, profil dokter, dan lokasi praktik dokter spesialis yang ada di kawasan Yogyakarta. Hasil dari pengujian sistem menunjukkan bahwa sistem informasi geografis ini layak dan dapat dipergunakan dengan hasil pengujian sistem menggunakan metode Alpha Test yang ditujukan kepada masyarakat dan dokter spesialis, menunjukkan persentase sangat setuju dan setuju mencapai 96,67\% dan kurang setuju mencapai 3,33\%.

4. Tinjauan studi dari penelitian Hanifah, N dkk, 2018, Muhammadiyah University of Surakarta, dalam Journal Department of Geography Education Vol.3/No.2

[Hanifah, N dkk 2018] 1. dalam Journal Department of Geography Education Vol.3/No.2 berjudul Analysis Of Tourist Travel Patterns Toward Health Care Facilities. Penelitian ini menjelaskan tentang salah satu sektor yang terkait erat dan cukup menentukan untuk pertumbuhan dan pengembangan sektor pariwisata adalah sektor kesehatan. Tujuan penelitian ini adalah untuk mengetahui keterjangkauan fasilitas pelayanan kesehatan dari pariwisata Candi Prambanan dan Candi Plaosan. Untuk mengetahui pola perjalanan wisatawan menuju fasilitas kesehatan. Sedangkan pada obyek wisata pariwisata Candi Prambanan tidak dapat menggunakan kendaraan pribadi karena jarak tempuhnya melebihi $3 \mathrm{~km}$, dan Pola perjalanan wisatawan ke sarana pelayanan kesehatan dikategorikan baik, karena wisatawan dapat mengakses layanan kesehatan dengan rute terdekat dan fasilitasmemadai.

5. Tinjauan studi dari penelitian Malekmohammadi, B. \& Blouchi, L. R. 2014, University Of Tehran, dalam Ecological Indicators Journal Vol.41/No.1 
[Malekmohammadi, B. \& Blouchi, L. 2014] dalam Ecological Indicators Journal Vol.41 berjudul Ecological Risk Assessment Of Wetland Ecosystems Using Multi Criteria Decision Making And Geographic Information System. Penelitian ini menjelaskan tentanglahan basah beresiko dari berbagai faktor. Penerapan praktis dari penilaian risiko ekologi lahan basah akan menghasilkan pemahaman yang lebih baik tentang bagaimana tekanan fisik, kimia, dan biologis mempengaruhi lahan basah dan akan menyediakan kerangka kerja bagi manajemen lahan basah yang bijaksana.Sistem Informasi Geografis (SIG) digunakan untuk mengembangkan peta dengan pemolesan dari pemutarpemutar sesuai dengan kebutuhan.

\section{PEMECAHAN MASALAH}

Berdasarkan hasil analisa yang dilakukan, permasalahan-permasalahan yang terjadi pada masyarakat yang ingin berwisata ke kota Tangerang terutama masalah kurangnya informasi lokasi membutuhkan jalan keluar yang bisa menangani masalah tersebut dengan cepat dan mudah. Adapun alternatif pemecahan masalah tersebut adalah sebagai berikut :

a. Penulis mengusulkan sebuah sistem yang berbasiskan website yang dapat di gunakan dengan mudah di akses oleh wisatawan

b. Menjadikan informasi wisata yang lebih modern dan praktis untuk pencarian loaksi wisata

c. Website yang di usulkan dapat menampilkan data informasi tentang sejarah wisata yang berada di kota Tangerang

d. Menampilkan informasi jalan menuju lokasi wisata yang ingin dituju.

e. Menampilkan peta lokasi wisata serta menampilkan gambar objek wisata untuk menjadikan daya tarik wisatawan

\section{PEMBAHASAN DAN HASIL}

Perancangan aplikasi ini dibuat dengan menggunakan alat bantu UML (Unified Modelling Languange) untuk membuat diagram yang menggambarkan aplikasi ini. Diagram yang digunakan adalah sebagai berikut. 
A. Use Case Diagram Website Informasi Wisata

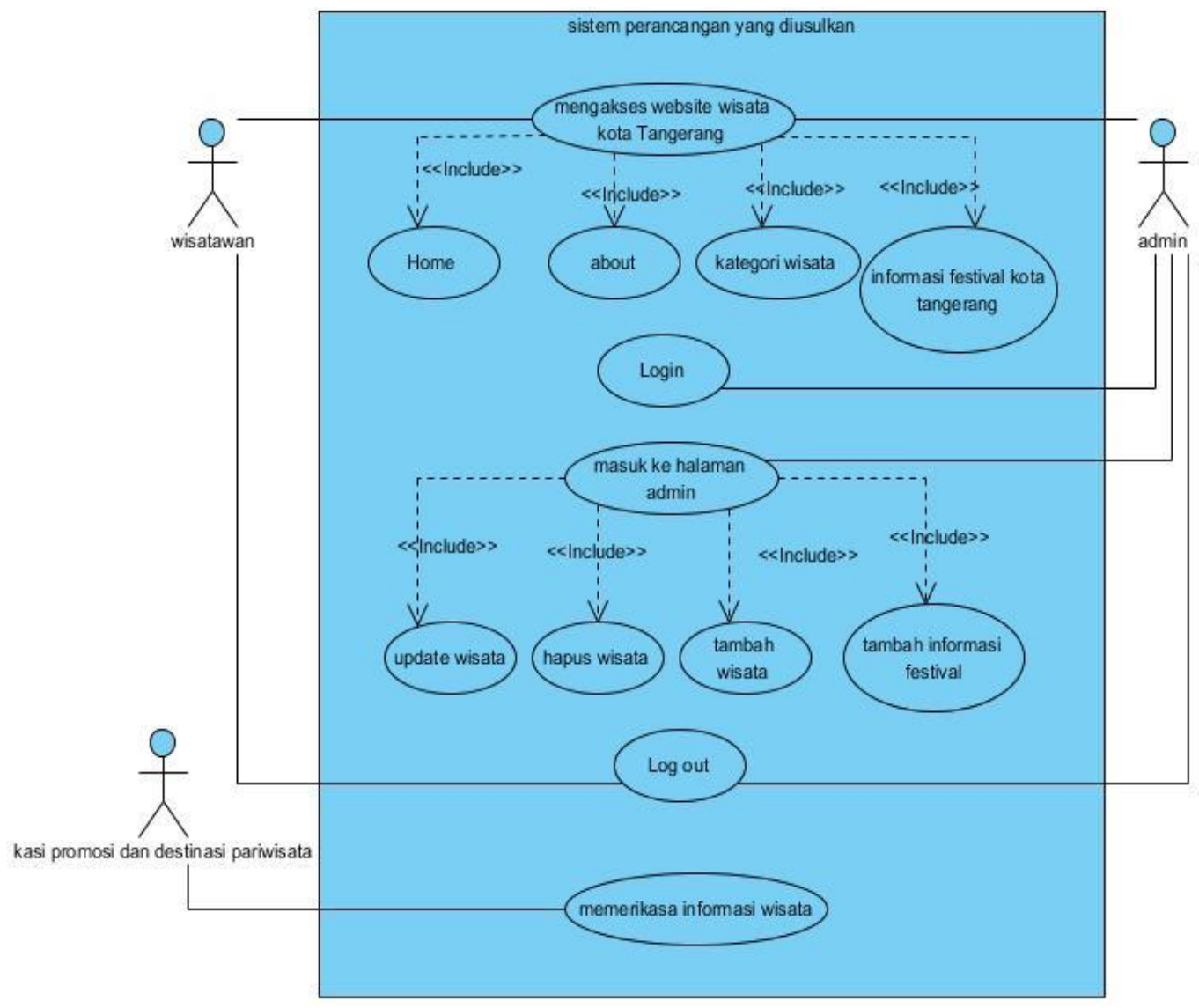

Gambar 1. Use Case Diagram Website Informasi Wisata

Berdasarkan gambar use case diagram diatas terdapat :

a. Satu (1) buah sistem yang meliputi seluruh kegiatan sistem pencarian wisata di kota Tangerang.

b. Tiga (3) aktor yang melakukan kegiatan yaitu : wisatawan, admin dan kasi promosi dan destinasi pariwisata.

c. Lima (5) use case dan delapan (8) include yang di lakukan oleh aktor-aktor tesebut. 
B. Class diagram website informasi wisata

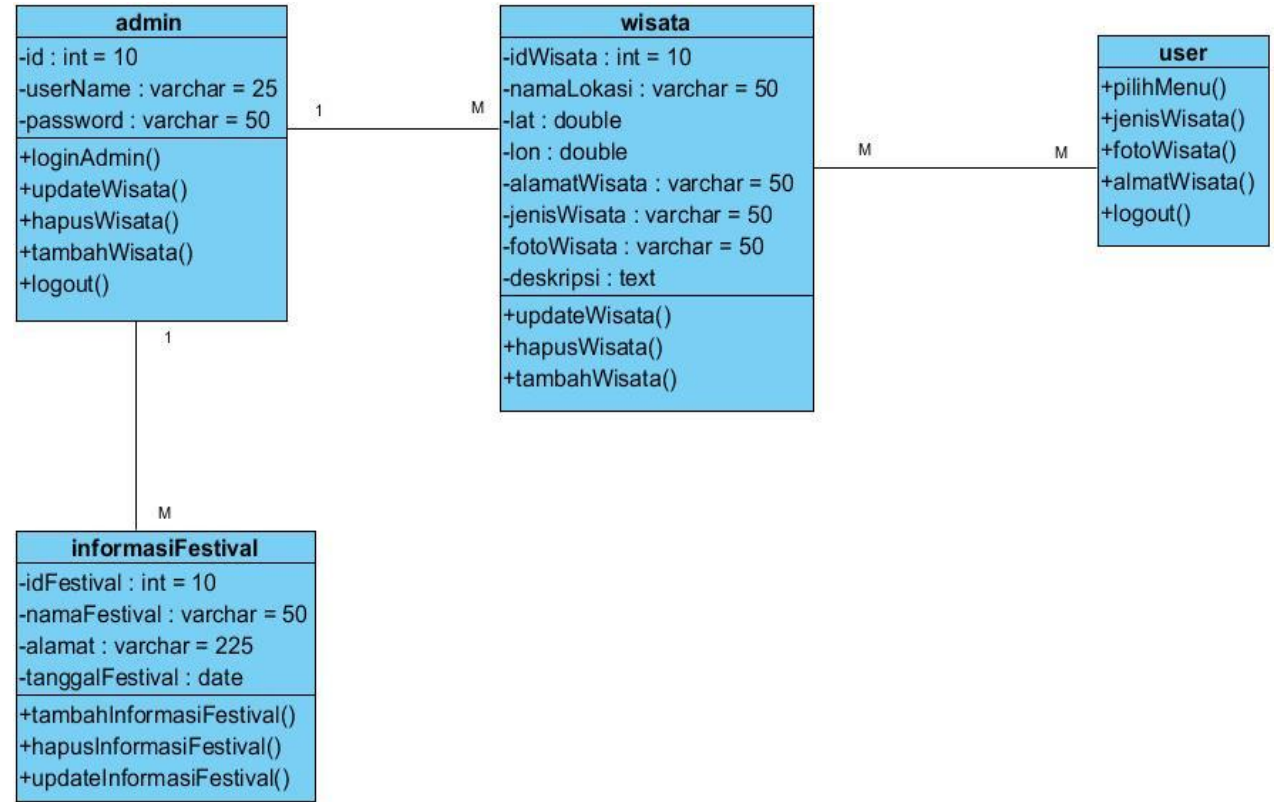

Gambar 2. class diagram informasi wisata

Berdasarkan gambar diatas terdapat empat (4) tabel class diagram yaitu : tabel admin, tabel wisata, tabel informasi festival dan tabel wisatawan

\section{IMPLEMENTASI SISTEM}

A. Tampilan Menu Home Wisata Kota Tangerang

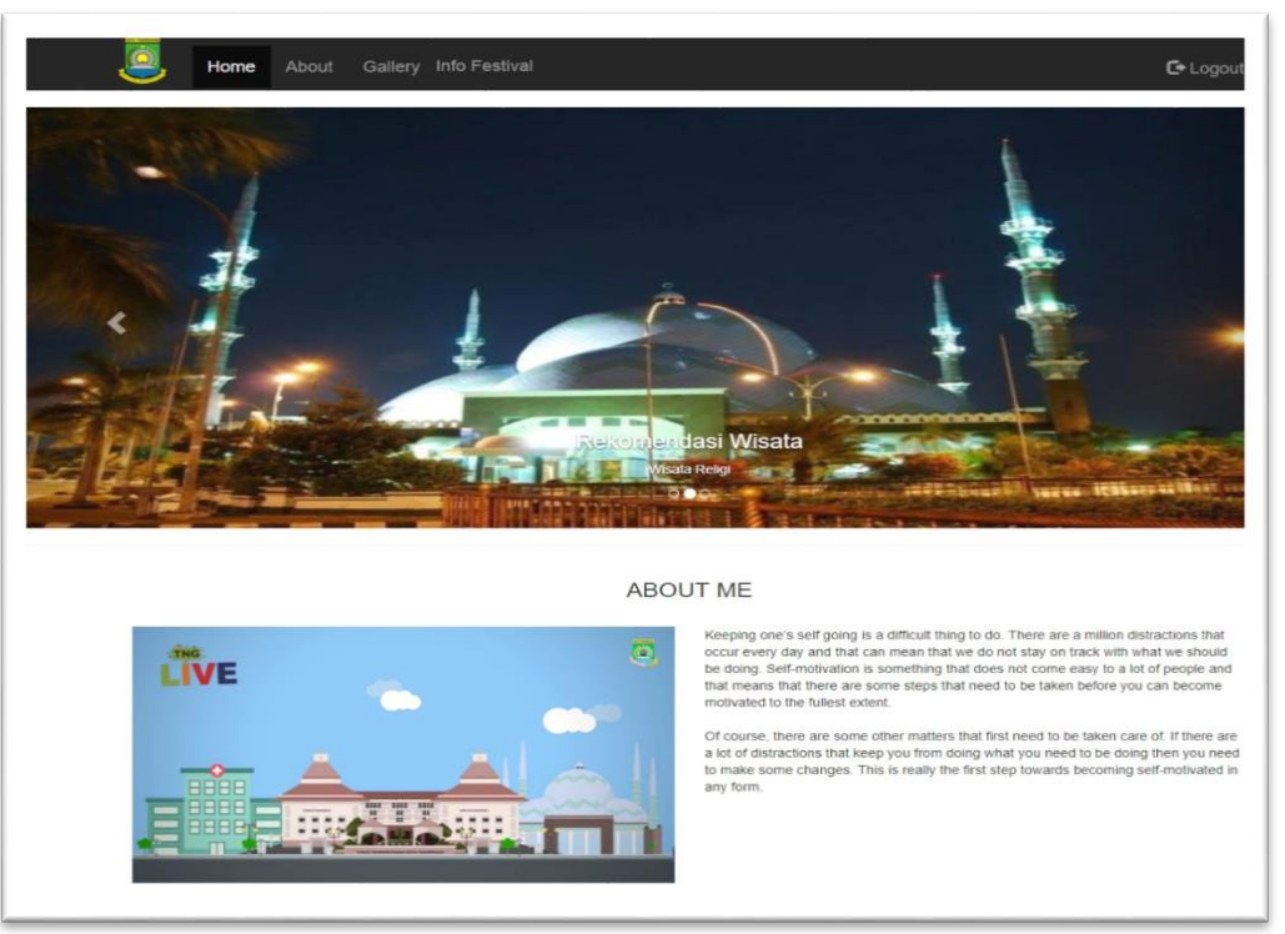

Gambar 3. tampilan menu home wisata kota Tangerang. 
Gambar 3 merupakan tampilan menu utama dari website wisata kota Tangerang dimana masyarakat bisa memilih menu yang di sediakan untuk mencari objek wisata yang ingin dilihat

B. Tampilan Menu Kategori Wisata

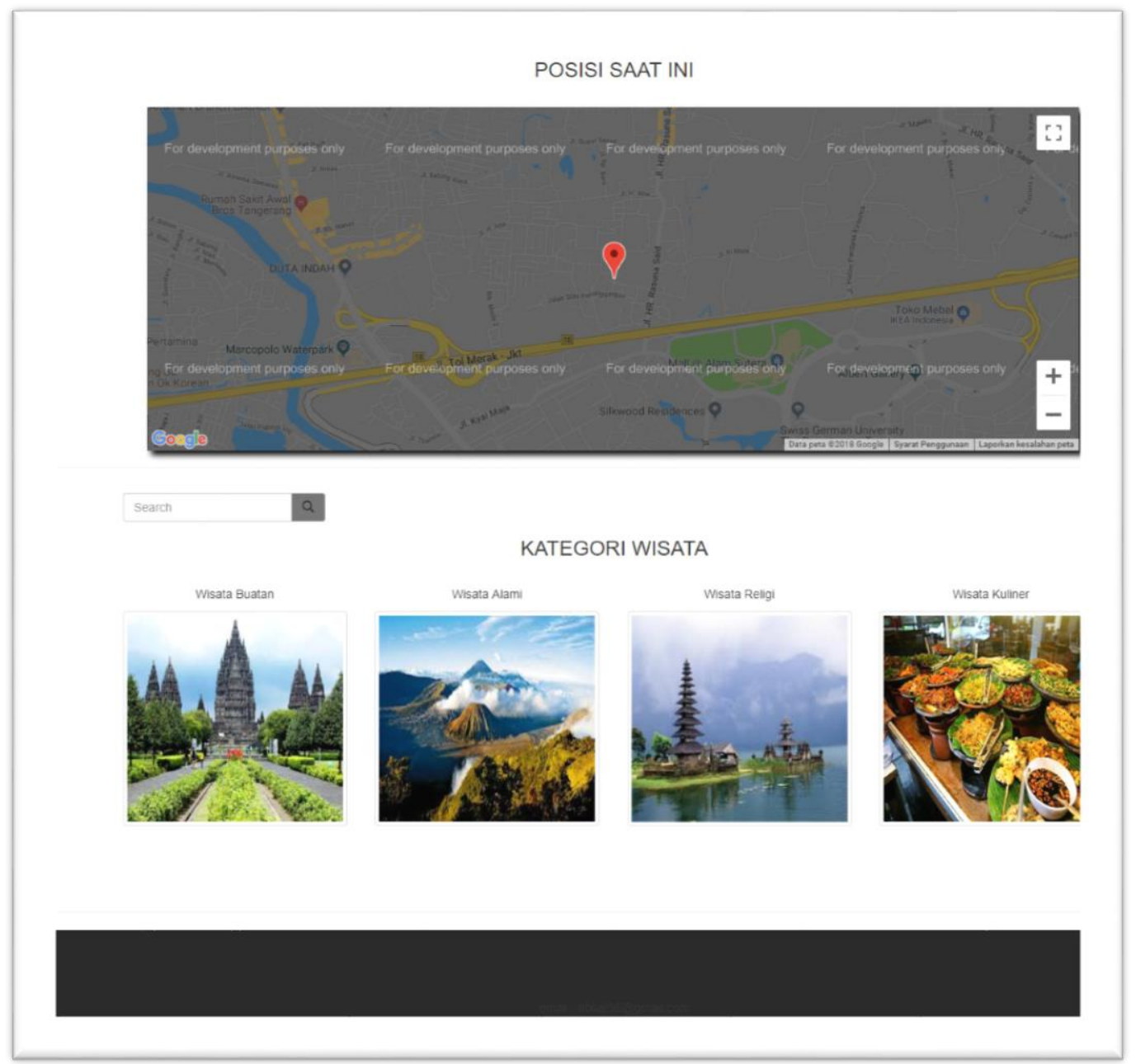

Gambar 4. tampilan menu kategori wisata

Pada gambar 4 merupakan tampilan menu kategori wisata kota Tangerang dimana pengguna bisa mencari wisata dari menu search atau bisa juga memilih 4 gambar kategori wisata di antaranya wisata buatan, wisata alami, wisata religi dan wisata kuliner. 
C. Tampilan Menuju Lokasi Wisata

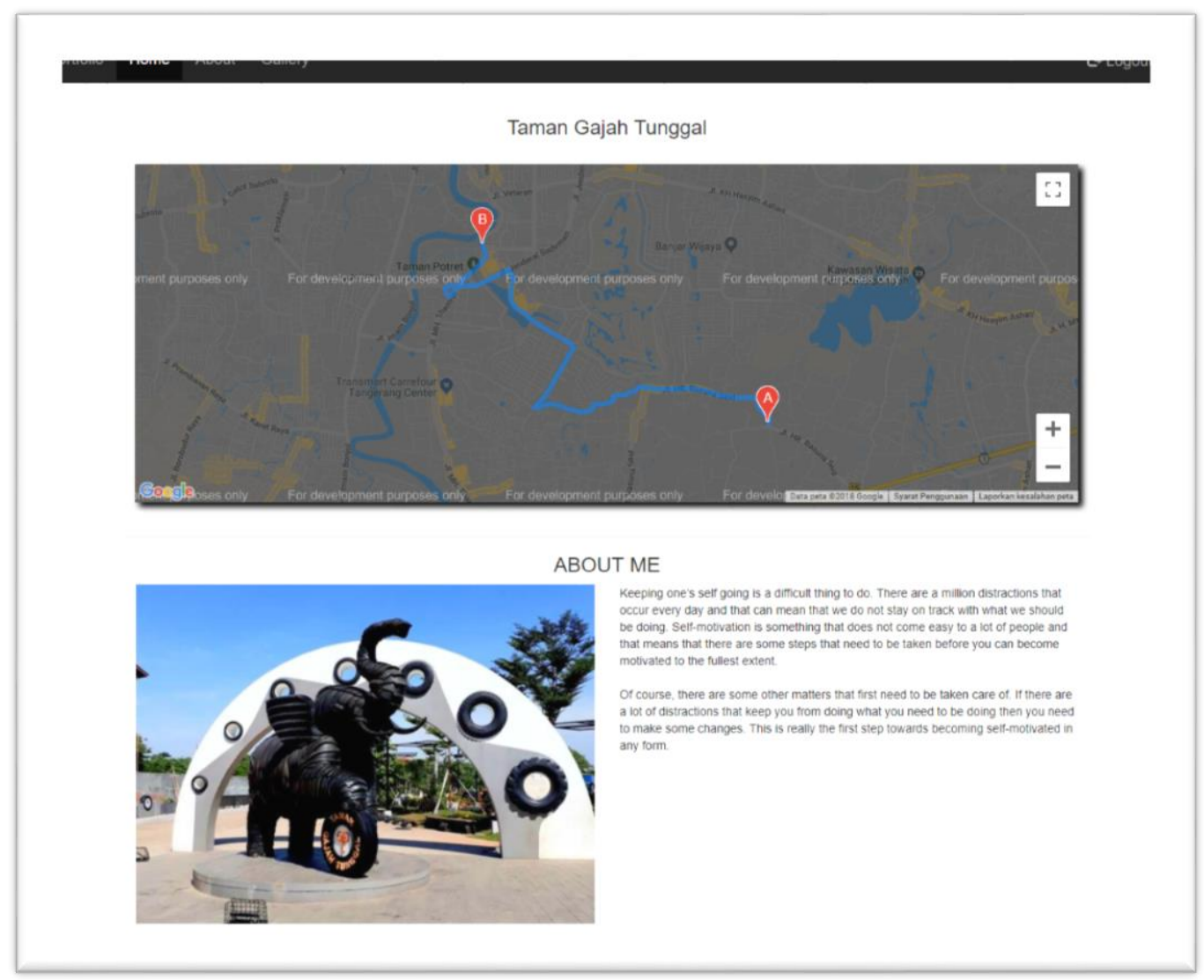

Gambar 5. tampilan menju lokasi wisata

Gambar 5 merupakan tampilan menuju lokasi wisata yang ingin di tuju wisatawan di menu ini juga menunjukan foto wisata, cerita wisata dan menampilkan arah atau jalan menuju lokasi wisata yang diinginkan. 
D. Tampilan menu info festival

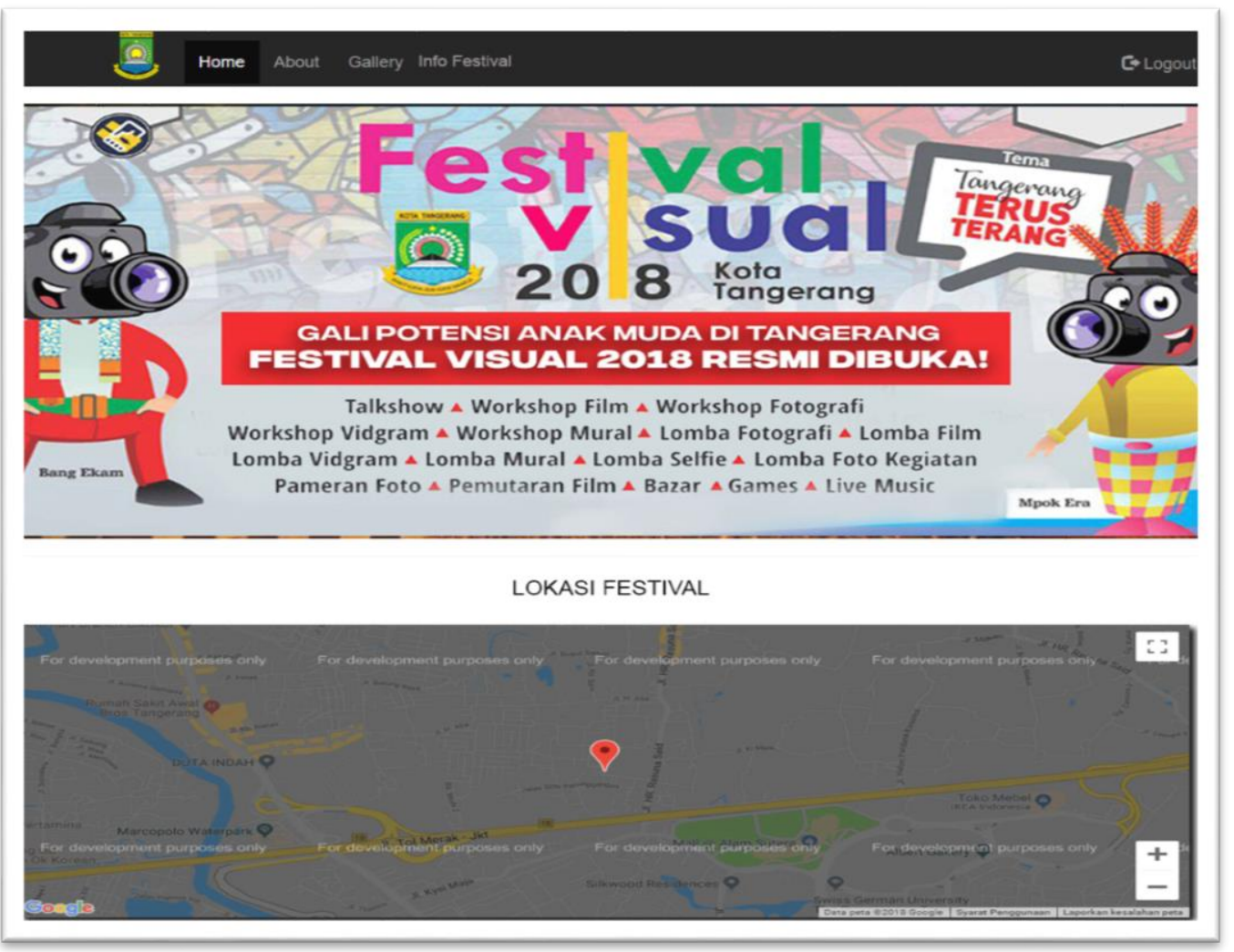

Gambar 7. tampilan menu festival

Gambar 7 merupakan tampilan menu informasi festival di mana pada menu ini user dapat mengetahui informasi festival apa saja yang akan diadakan di Kota Tangerang serta menampilkan lokasi di mana festival itu berada.

\section{KESIMPULAN}

Berdasarkan hasil penelitian yang telah dilakukan pada Dinas Budaya dan Pariwisata Kota Tangerang maka dapat diambil kesimpulan sebagai berikut :

1. Pengguna dapat melihat lokasi wisata dan dapat melihat jalan menuju lokasi wisata yang diinginkan dengan menggunakan sistem informasi geografis berbasisi website.

2. Dengan merancang sebuah sistem yang terkoputerisasi dapat memudahkan pengguana atau wisatawan untuk mencari objek wisata dengan tepat.

3. Untuk mempromosikan wisata kota Tangerang 


\section{SARAN}

Setelah menganalisa dan mempelajari pemetaan lokasi pariwisata kota Tangerang seperti yang dibahas sebelumnya, maka penulis memberikan saran atau usulan sebagai berikut :

1. Sebaiknya aplikasi tidak hanya menggunakan bahasa Indonesia, bisa juga menggunakan bahasa inggris agar wisatawan mancanegara dapat menggunakan website yang diusulkan.

2. Karena ini berbasis website pastinya menggunakan internet, ada baiknya dikembangkan lagi untuk digunakan secara offline.

\section{DAFTAR PUSTAKA}

Supriati, R., Santoso, S., \& Juniarno, A. 2014. Pemanfaatan Sistem Informasi Geografis Berbasis Web untuk Penyebaran Lokasi Puskesmas di Kota Tangerang. Jurnal Teknik Informatika dan Sistem Informasi, Vol.1/No.1, $42-50$

Masykur, F. 2014. Implementasi sistem informasi geografis menggunakan google maps api dalam pemetaan asal mahasiswa. Simetris Jurnal Teknik Mesin, Elektro dan Ilmu Komputer, Vol.5/No.2, 181-186.

Dyah, N. R., \& Arsandy, E. R. 2016. Sistem Informasi Geografis Tempat Praktek Dokter Spesialis di Provinsi DI Yogyakarta Berbasis Web. Informatika Mulawarman Jurnal Ilmiah Ilmu Komputer, Vol.10/No.1, 65-72.

Hanifah, N., Pujianingsih, M. N. C., Pratiwi, D. H., Fahmi, L. A., Anhari, F., \& Albayani, T. 2018. Analysis Of Tourist Travel Patterns Toward Health Care Facilities. Geosfera Indonesia, Journal of Geogra

Malekmohammadi, B., \& Blouchi, L. R. 2014. Ecological risk assessment of wetland ecosystems using multi criteria decision making and geographic information system. Ecological Indicators, 41, 133-144. 